\title{
Original
}

\section{Development of a Self-Management Scale of PMS during Childrearing Periods and Examination of its Validity and Reliability}

\author{
Mayumi Hamasaki ${ }^{1}$ and Yoko Tokiwa ${ }^{2}$ \\ 1 Miyazaki Prefectural Nursing University, 3-5-1 Manabino, Miyazaki, Miyazaki 880-0929, Japan \\ 2 Gunma University Graduate School of Health Sciences, 3-39-22 Showa-machi, Maebashi, Gunma 371-8514, Japan
}

\begin{abstract}
Objective: The objective of this study was to develop a "Self-Management Scale of Premenstrual Syndrome (PMS) during Childrearing Periods" for mothers currently raising children and to examine the validity and reliability of the scale. Methods: Participants included mothers aged 20 to 44 with children six or under. We distributed anonymous, self-administered questionnaires to 1,640 mothers and received 878 responses; 797 were selected for analysis. The questionnaire included 48 items measuring symptoms that accompany PMS during childrearing periods. Results: Five factors were extracted from the 38-items following exploratory factor analyses using principle and promax rotation: (1) feeling of emotional instability before menstruation, (2) positive emotional changes after menstruation, (3) perception of husband's support before and after menstruation, (4) reduced energy before menstruation, and (5) unpleasant physical symptoms before menstruation. The scale positively correlated with the Parenting Stress Short Form and the Edinburgh Postnatal Depression Scale and negatively correlated with the social support scale, confirming criterion validity. The Cronbach's $\alpha(0.79$ to 0.94$)$ and split-half reliability $(\rho=0.74)$ suggest that the scale is reliable. Conclusions: The scale developed in this study is valid and reliable, suggesting usefulness for PMS self-management for mothers currently raising children.
\end{abstract}

\begin{tabular}{l} 
Article Information \\
\hline Key words: \\
Premenstrual syndrome, \\
childrearing mothers, \\
self-management, \\
scale validity, \\
scale reliability \\
\hline Publication history: \\
Received: November 15, 2017 \\
Revised: January 10, 2018 \\
Accepted: January 19, 2018 \\
\hline Corresponding author: \\
Mayumi Hamasaki \\
Miyazaki Prefectural Nursing University, 3-5-1 Manabino, \\
Miyazaki, Miyazaki 880-0929, Japan \\
Tel: +81-985-59-7747 \\
E-mail: hamasaki@mpu.ac.jp \\
\hline
\end{tabular}

\section{Introduction}

In the West, premenstrual syndrome (PMS) is gaining attention both clinically and socially because, for example, there is an increase in child abuse by mothers before menstruation. ${ }^{1}$ Research suggests that a wide range of factors are closely related to PMS incidents, including stress, ${ }^{2}$ lifestyle, ${ }^{3}$ latent iron-deficiency anemia, ${ }^{4}$ and menstruation problems. ${ }^{5}$ Thus, the majority of studies in both the foreign and Japanese literature are related to pathology, diagnosis, and treatment. According to the "Guidelines for PMS Patients" by the American Society for Reproductive Medicine, ${ }^{6}$ there are 9 psychiatric, 14 physical, and 12 behavior-related symptoms of PMS. Recent work suggests PMS may occur because of a high sensitivity to luteal hormones in the serotonergic neurons, which induce depressive states. ${ }^{7,8}$

According to Dalton, ${ }^{9}$ the incidence of PMS after the first and fourth childbirth is $87 \%$ and $100 \%$, respectively. Thus, childbirth may be a predictive factor for the onset of PMS. A study of 769 women found that $59 \%$ of the women with PMS developed postnatal depression compared to only $14 \%$ of women without PMS. The same study also found that PMS was correlated to the development of postnatal depression, and $86 \%$ of the 300 women with postnatal depression also had an onset of PMS during the childrearing period. Furthermore, Dalton ${ }^{10}$ pointed out that mothers with PMS were likely to use problematic parenting practices, including using violence on their children. 
According to Lewis, ${ }^{11}$ the issue of child-abuse and PMS. was reported as the only case of criminal trials in the US that had been commuted due to PMS.

Here in Japan, the increasing number of cases of child abuse led to the creation of "Healthy Parent and Child 21," which aims to decrease the incidence of suspected postnatal depression. In the final assessment, the percentage of mothers who reported abusing their child/children aged 3 and 4 months, 18 months, and 3 years were $4.2 \%, 8.5 \%$, and $14.2 \%$, respectively, suggesting the rate is higher in mothers who have older children. In addition, the Ministry of Health, Labour and Welfare launched Home Visit Services for Every Infant in 2007. As part of these awareness campaigns, interest in postnatal depression as a cause of child abuse is growing, not only in local governments, but also in regional perinatal care organizations that are actively conducting postnatal depression screenings for mothers starting when they are pregnant until four months after the child is born using the Edinburgh Postnatal Depression Scale (EPDS). Scales are also being developed to quantify stressors related to childrearing for both the children and mothers' sides related to childrearing as stressors (PSI-SF). However, of these studies, only a few consider PMS to be a factor of mothers' sides as a stressor. Furthermore, menstruation resumes approximately seven months after birth; however, there are no public support systems available for mothers beyond 4 months after childbirth. Thus, it is difficult for existing mother and child health programs to screen women for PMS. Assessing the presence of PMS and PMS-related symptoms in addition to screening for postnatal depression, will provide more opportunities to support the psychological health of mothers with infants and potentially contribute to the prevention of infant abuse.

There was a record-high of 103,260 consultation cases related to child abuse reported at child consultation centers nationwide in FY2015. This number is increasing annually and is currently about 9.3 times the number of cases in FY1999, before the child abuse prevention law went into effect. Cases with children aged 0 to 3 years account for about $70 \%$ of the child abuse consultations. Most of the cases are mental abuse (47.2\%), followed by physical abuse $(27.7 \%)$.

According to the verification report of deaths caused by child abuse in FY2016, 70\% of children who died of abuse were under 3 years old, and about $50 \%$ of the perpetrators were their biological mothers. It was analyzed that child-abuse background includes irritation and aggressive urge associated with childrearing ${ }^{12}$ Irritation due to PMS is believed to be one trigger leading to these infant abuse death cases.

According to Harada ${ }^{13}$ in the Health, Labour and Welfare Ministry's 2003 Hyogo report, even when mother's hold firmly positive emotions towards their children, such as believing their children are precious, many mothers also complain of a "sense of burden from childrearing," such as feeling irritated towards their children. Hamasaki ${ }^{14}$ conducted interviews and found that mothers who were diagnosed with PMS expressed negative feel- ings before the onset of menstruation (e.g., "I have been feeling irritated since my baby became about 18 months old," "I scold my child in frustration," and "I scold my child and make him/her cry, and when he/she apologizes to me, I feel bad about myself."). In this same study, mothers self-monitored changes in their physical, mental, and social symptoms associated with their basal temperature and menstruation cycle, and Hamasaki ${ }^{14}$ found that when the subjects noticed that the onset of those symptoms concentrated in the period before menstruation, they realized that their unfavorable behaviors were triggered by PMS and then became tolerant of themselves. Namba ${ }^{15}$ reported that satisfaction with their social support helped reduce daily life stress and alleviate symptoms associated with menstruation.

This study recognized that if mothers were able to realize the relationship between PMS symptoms and irritation by utilizing a scale that helps them recognize the presence or absence of PMS as well as the severity of those symptoms, they would be able to enhance their internal motivation to cope with the childrearing stress associated with PMS. In doing so, mothers would be able to select effective coping behaviors to improve self-management. Therefore, the objective of the study was to develop a "Self-Management Scale of PMS during Childrearing Periods" to contribute to the self-management of PMS symptoms associated with monthly menstruation after childbirth and to examine the validity and reliability of that scale.

\section{Operational Definitions of Terms \\ 1) Premenstrual Syndrome (PMS)}

Premenstrual syndrome (PMS), also known as premenstrual tension, is defined in the Japan Society of Obstetrics and Gynecology glossary as "emotional or physical symptoms that last 3 to 10 days before menstruation and lessen or disappear with the onset of menstruation." In this study, we used updated PMS diagnostic criteria $^{16}$ and defined PMS as "physical, mental, and social symptoms that begin at least 3 to 10 days before the start of menstruation and disappear when menstruation starts or within four days of the start of menstruation."

\section{2) Childrearing Period}

A mother's childrearing period is defined as the period from the birth of her first child until her last child enters elementary school.

\section{3) Self-Management}

Barlow et al. ${ }^{17}$ define self-management as "the ability to manage the unique symptoms and treatments, physical and psychosocial effects, and lifestyle changes concomitant with a chronic illness." Self-management includes the ability to monitor one's own condition and to awaken the cognitive, behavioral, and emotional responses needed to maintain a satisfying quality of life. This study defines self-management as the ability to monitor and manage the physical, mental, and social symptoms related to PMS during the childrearing period. 


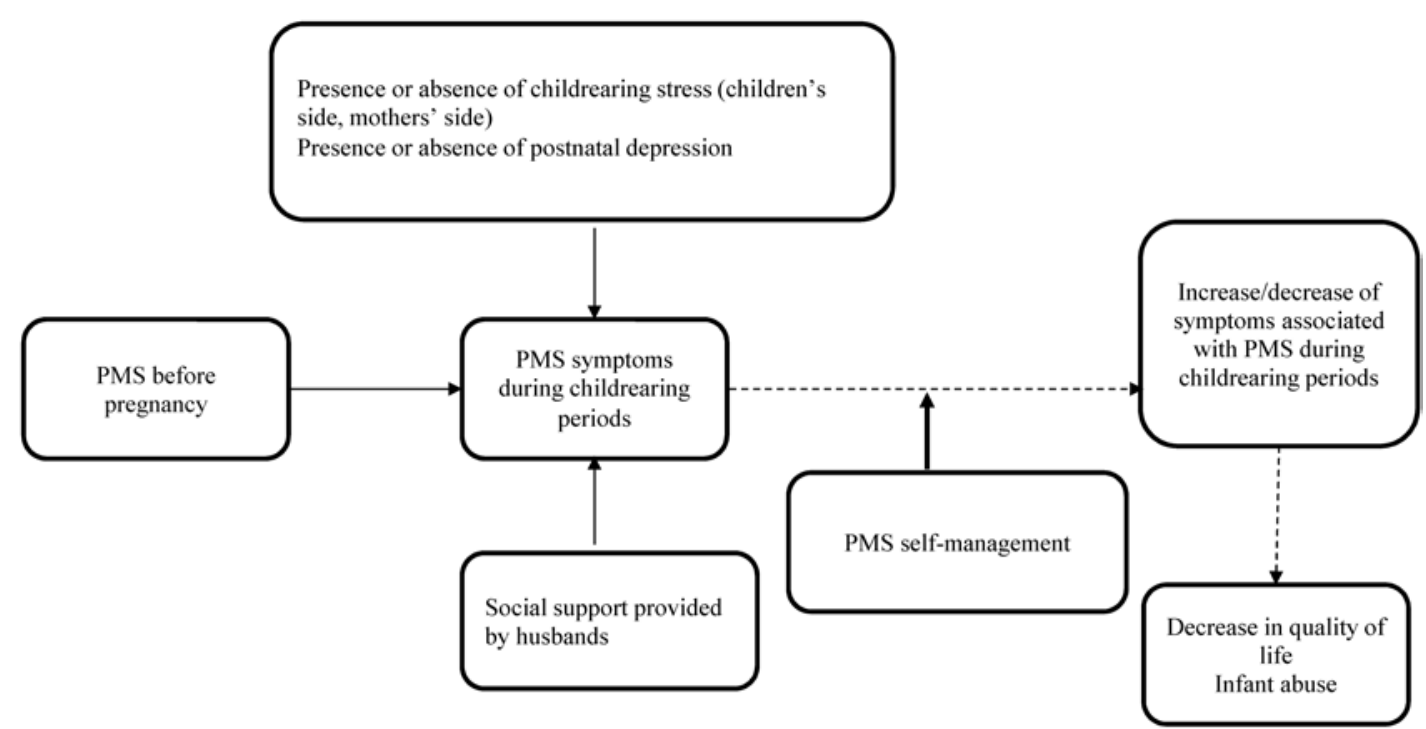

Fig. 1 Relationship between factors affecting Premenstrual Syndrome (PMS) during childrearing period and aggravation of premenstrual symptoms

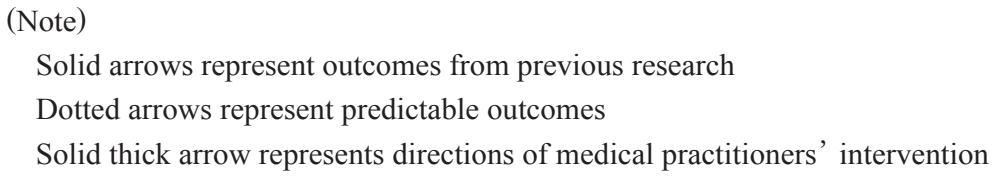

\section{Objectives}

The objectives of this study were to develop a "Self-Management Scale of PMS during Childrearing Periods" and to examine the validity and reliability of the scale.

\section{Materials and Methods}

\section{Conceptual Framework for Creating the Self-Man- agement Scale (Figure 1)}

A study by Dalton ${ }^{9}$ found that PMS symptoms occur with the return of menstruation for people who had PMS before becoming pregnant, suggesting a relationship between pre-pregnancy PMS symptoms and PMS symptoms during the childrearing period. Previous studies have also found that personal factors like stress and postnatal depression and social factors like social support have an effect on the increase or decrease of PMS symptoms.

PMS during the childrearing period may be caused by childrearing stress (both in the children and in the mother), postnatal depression, and social support provided by husbands. When mothers who are childrearing can monitor and self-manage their PMS symptoms, they may be able to control the severity of their PMS symptoms, leading to, for example, reduced irritation accompanying PMS. The increase or decrease of symptoms associated with PMS during childrearing periods may impact the risk of infant abuse due to the mother's quality of life or childrearing stress.

We developed the "Self-Management Scale of PMS during Childrearing Periods" based on the hypothesis that childrearing stress, postnatal depression, and social support from the husband are related to PMS symptoms during the childrearing period. Figure 1 displays the conceptual framework.

\section{Research Design}

This research had a cross-sectional and descriptive design.

\section{Facilities and Individual Subjects \\ 1) Facilities.}

The facilities in this study included 10 day care facilities and three preschools in the suburbs of A Prefecture.

\section{2) Individual Subjects.}

The subjects of this study were mothers aged 20 to 44 who had resumed menstruating after childbirth and who were engaged in raising their youngest child, between zero and six years old. This age group was selected because, according to Kawase, ${ }^{18}$ women experience PMS more strongly starting at age 25 . However, the Health, Labour and Welfare Ministry issued a report in 2015 that noted that childbirth can trigger the onset of PMS during the childrearing period ${ }^{9}$ in women aged 20 through 44 account for $98.7 \%$ Thus, the mothers included in this study were between 20 and 44 years old. We excluded teenage subjects in this study because many women in that age group have a combination of dysmenorrhea and PMS (PEMS). Furthermore, the climetric is said to represent an average of around 10 years before or after menopause, and, because the Japan Society of Obstetrics and Gynecology defines this age as being from 45 to 55 , we excluded subjects over the age of 44 . 


\section{Data Collection Period}

This study was conducted from May 2014 to December 2014.

\section{Research Methods}

1) Development of the "Self-Management Scale of PMS during Childrearing Periods"

(a) Establishing the items for the "Self-Management Scale of PMS during Childrearing Periods"

When we developed the "Self-Management Scale of PMS during Childrearing Periods," we identified PMS-related symptoms before menstruation begins (the luteal phase) and symptoms after the start of menstruation (the follicular phase) for mothers in their childrearing period. The questions consisted of the following five categories: psychiatric symptoms before the start of menstruation, social symptoms before the start of menstruation, physical symptoms before the start of menstruation, positive emotions after the start of menstruation, and support from the husband (partner) before and after the start of menstruation. We included 50 items that became the basis of the "Self-Management Scale of PMS during Childrearing Periods" using symptoms extracted from the 34 cycles of basal body temperature charts of 12 mothers aged 20 to 44 currently raising children between one and three and added PMS symptoms obtained from a literature review on studies about PMS. ${ }^{19}$

The responses were on a five-point Likert scale ranging from $1=$ strongly disagree, $2=$ disagree, $3=$ neither agree nor disagree, $4=$ agree. to $5=$ strongly agree. Higher scores indicated greater PMS symptoms.

\section{(b) Examining Face Validity}

After removing those items with redundant content or expressions, 48 items were examined for their face validity. The PMS self-management during childrearing items included: "psychiatric symptoms before the start of menstruation" (14 items); "social symptoms before the start of menstruation" (11 items); "physical symptoms before the start of menstruation" ( 8 items); "positive emotions after the start of menstruation" (7 items); and "support from the husband (partner) before and after the start of menstruation" ( 8 items). We also conducted a pre-test using 10 mothers currently raising children between zero and six years old and modified or corrected the wording of the items. The mothers who participated in the pre-test completed the questionnaire in approximately 5 minutes.

\section{2) Data Collection Methods}

Before conducting the survey, we sent a study request letter and study plan to the heads of each cooperating facility and obtained consent for the study and the number of participating mothers using a sealed reply letter. We then sent request letters, questionnaires, and reply envelopes to each cooperating facility for each participant and asked the head of the facility or the managing daycare worker to distribute them. We used envelopes with double-sided tape for the reply envelopes so that they could not be reopened after the subjects sealed them. About one month after sending the questionnaires, we set up collection boxes at the cooperating facilities and left them there to collect the responses.

\section{3) Measurement Tools for Diagnosing PMS}

Because the "Self-Management Scale of PMS during Childrearing Periods" measures changes in PMS-related symptoms, we used a simple premenstrual syndrome test, PMS Memory, to diagnose PMS. PMS Memory $^{20}$ is a real-time journaling recording method (i.e., prospective recording) developed in the US based on the Utah PMS Calendar II. The Utah PMS Calendar II asks for assessments in seven levels, but PMS Memory has three practical and simple assessment levels. PMS symptoms consist of 25 physical, 15 psychiatric, and 12 social symptoms. PMS symptoms were marked as "1" $=$ "somewhat present but no effect on daily life"; " 2 " = "present to the point of effecting daily life"; or " 3 " = "intense." Mothers whose responses included symptom severity levels between 2 and 3 were considered to be in the group with PMS. Mothers who had symptoms but were ranked as a 1 were considered to be in the group without PMS.

4) Measurement Tools for Examining Criterion Validity

(a) Parenting Stress Index Short Form (PSI-SF, 19 items)

The Parenting Stress Index was developed by Abidin $^{21}$ in the $1980 \mathrm{~s}$, and a Japanese edition of the PSI manual was published in 2006; a practical edition, the PSI-SF, was developed, and its reliability has been confirmed. ${ }^{22,23}$ The PSI-SF has a total of 19 items: nine for stress related to the characteristics of children and 10 related to mothers themselves. The responses to each item are on a five-point scale: "1" = strongly disagree," " $2=$ "disagree," " 3 " = "neither agree nor disagree," " 4 " $=$ "agree," and " 5 " = "strongly agree." Possible scores range from 19 to 95 points, and higher scores indicate a higher level of childrearing stress. Because parenting stress is thought to impact PMS, we used the PSI-SF as an external standard that measures sides related to both the child and the mother. We hypothesized that the premenstrual (luteal phase) score of the "Self-Management Scale of PMS during Childrearing Periods" would positively correlate with the PSI-SF and that the score after the start of menstruation (follicular phase) would have no correlation.

\section{(b) Measurement Tools for Diagnosing Postnatal Depression}

Postnatal depression can cause PMS during the childrearing period and change premenstrual symptoms. ${ }^{9}$ Therefore, we used the Edinburgh Postnatal Depression Self-Assessment Scale (EPDS), which is used by many local governments and perinatal care organizations, to screen for postnatal depression, as a part of the "Healthy Parent and Child 21 Program." Since the EPDS was developed by Cox et al. ${ }^{24}$ in the UK in 1987, it has become widely popularized internationally. Thus far, it has been translated into over 20 languages and has been established as a screening test for postnatal depression. This study used the Japanese edition of the EPDS ${ }^{25}$ trans- 
lated by Okano. Participants responded to the 10 EPDS questions on a scale from 0 to 3 points, with total scores ranging from 0 to 30 points. Higher scores indicate stronger instances of postnatal depression. In the Japanese edition, the cutoff point is $8 / 9$, with scores of 9 and above considered highly likely for postnatal depression. In this study, those with a score of 9 or more points were considered to have postnatal depression.

\section{(c) Social Support Scale (24 items)}

The Social Support Scale developed by Nakamura et $a .^{26}$ is a scale that measures the degree to which a mother feels supported by her husband, parents and relatives, friends, and neighbors; the reliability of this scale has been verified. The scale consists of 24 items, including instrumental, evaluative, and emotional support. The scale is scored using a five-point self-assessment method, with possible scores ranging from 24 to 120 points. Higher scores indicate higher levels of social support.

This study used the Social Support Scale as an external standard. We hypothesized that the premenstrual (luteal phase) score of the "Self-Assessment Scale of PMS during Childrearing Periods" would negatively correlate with the "Social Support Scale" and would positively correlate with the "Social Support Scale (Husband)" over the entire menstrual cycle and that the score after the start of menstruation (follicular phase) would show no correlation.

\section{Data Analysis Plan}

Questionnaires with a non-response rate of over $10 \%$ on the following items were excluded from the analysis: basic attributes, "PMS Self-Management during Childrearing Period," "PSI-SF," "EPDS," and "Social Support Scale." Missing values in questionnaires that had a non-response rate of less than $10 \%$ were replaced with the mode. Mother-and-child nuclear family and mother-and-child extensive family (total $n=$ 29) included mothers with a not-legally-married partner who is the father of their child / children and filled in the items regarding 'partner' in "PMS Self-Management during Childrearing Period" and "Social Support Scale."

We calculated descriptive statistics for each variable, conducted Exploratory Factor analyses (EFA) to examine construct validity, and used the PSI-SF, EPDS, and Social Support Scale to examine criterion validity. To examine the reliability of the scale, we calculated Cronbach's $\alpha$ and used a split-half reliability method (Spearman-Brown's formula). To examine differences in the average values, if homoscedasticity was hypothesized, we conducted a t test. If homoscedasticity was not hypothesized, we used the Welch's method. We used statistics software SPSS version 21.0 for the analyses and worked under the supervision of a statistics expert.

\section{Ethical Considerations}

Participants were provided with a document that explained the following: the objectives, significance, and methods of the study; the privacy protections; that the information gathered in the surveys would be processed statistically and only used in the present study; that participation in the study was voluntary; and that there would be no disadvantage incurred by refusing to participate. We considered completed questionnaires submitted in the collection box to be an indication of consent. This study was conducted after receiving approval (Approval No. 25-49) from the Gunma University School of Medicine Epidemiology Ethics Review Committee.

\section{Results}

\section{Subject Attributes}

The survey was distributed to 1,640 people, and we received responses from 878 (response rate of 53.5\%). Of those, we excluded 79 responses from analysis for the following reasons: the mother's age was 45 or over (29), the mother does not menstruate (2), there were no responses about premenstrual symptoms (42), or the questionnaire had a $10 \%$ or higher non-response rate to questions (8). There were 797 valid responses (valid response rate of $90.8 \%$ ).

The mothers' mean age was $34.6(\mathrm{SD} \pm 4.8)$ years (ranging from 20 to 44 years), and their menstruation had begun a mean of 8.5 ( $\mathrm{SD} \pm 6.0)$ months after giving birth. A total of 648 mothers $(81.3 \%)$ had a normal menstrual cycle (25 to 38 days), 454 (57.0\%) had PMS, and 343 $(43.0 \%)$ did not have PMS.

The mean number of children was $2(\mathrm{SD} \pm 0.8)$. The age of the youngest child was 0 for 83 mothers $(10.4 \%), 1$ to 2 years for 277 mothers $(34.8 \%)$, and 3 to 6 years for 429 mothers $(53.8 \%)$. With respect to working status, 535 were employed $(68.2 \%)$, and 45 were on maternity leave $(5.7 \%) ; 205$ were full-time homemakers $(26.1 \%)$. The family structure was that of a nuclear family for 662 of the participants $(83.1 \%)$ and that of an extended family for $106(13.3 \%)$. There were 15 fatherless nuclear families (1.9\%) and 14 fatherless extended families (1.7\%) (see Table 1).

\section{Scores for Each Scale Used in this Study (see Table 2) 1) Simple PMS Test Scores}

Scores for the "Simple PMS Test" ranged from a minimum of 0 point to a maximum of 123 points, and the average score was $26.5(\mathrm{SD} \pm 24.0)$. The mean on the "Simple PMS Test" was $37.6(\mathrm{SD} \pm 24.6)$ for those with PMS and 11.9 (SD \pm 12.8$)$ for those without PMS. Those with PMS had significantly higher scores than those without PMS $(t[715.1]=17.6, p<0.01)$.

\section{2) PSI-SF Scores}

The range of scores for the PSI-SF was 19 to 95 points. The mean scores for the PSI-SF (Children's sides) were 21.2 (SD \pm 5.6 ) for the PMS group and 20.4 ( $\mathrm{SD} \pm 5.2)$ for the group without PMS. A comparison of the mean scores for these two groups did not show statistically significant differences in the average scores.

The mean scores for the PSI-SF (Mothers' side) were 22.9 (SD \pm 6.5 ) for those with PMS and 21.4 (SD \pm 5.9) for those without PMS. A comparison of the mean scores for these two groups showed that the mean score 
Table 1 Subject Attributes

\begin{tabular}{|c|c|c|}
\hline \multicolumn{3}{|l|}{ Item } \\
\hline Age & years (SD) & $34.6 \pm 4.8$ \\
\hline Postpartum & months (SD) & $8.5 \pm 6.0$ \\
\hline \multirow{2}{*}{ onset of menstruation } & min: months $(\%)$ & $2(15.3)$ \\
\hline & max: months $(\%)$ & $36(0.3)$ \\
\hline \multirow[t]{6}{*}{ Menstruation cycle } & $\mathrm{n}(\%)$ & \\
\hline & $<24$ days & $32(4.0)$ \\
\hline & 25 to 38 days & $648(81.3)$ \\
\hline & $>39$ days & $20(2.5)$ \\
\hline & Irregular & $83(10.3)$ \\
\hline & Unknown & $10(1.3)$ \\
\hline \multirow[t]{5}{*}{ Menstruation duration } & $\mathrm{n}(\%)$ & \\
\hline & $<2$ days & $1(0.1)$ \\
\hline & 3-7 days & $649(82.7)$ \\
\hline & $>8$ days & $110(14.0)$ \\
\hline & Irregular & $25(3.2)$ \\
\hline \multirow[t]{3}{*}{ Premenstrual Syndrome (PMS) } & $\mathrm{n}(\%)$ & \\
\hline & Positive & $454(57.0)$ \\
\hline & Negative & $343(43.0)$ \\
\hline Number of children & $\mathrm{n}(\mathrm{SD})$ & $2.0 \pm 0.8$ \\
\hline \multirow[t]{4}{*}{ Age of the youngest child } & $\mathrm{n}(\%)$ & \\
\hline & 0 year & $83(10.4)$ \\
\hline & $1 \sim 2$ years & $277(34.8)$ \\
\hline & $3 \sim 6$ years & $429(53.8)$ \\
\hline \multirow[t]{4}{*}{ Employment status } & $\mathrm{n}(\%)$ & \\
\hline & Employed & $535(68.2)$ \\
\hline & Maternity leave & $45(5.7)$ \\
\hline & Full-time homemakers & $205(26.1)$ \\
\hline \multirow[t]{5}{*}{ Family structure } & $\mathrm{n}(\%)$ & \\
\hline & Nuclear family & $662(83.1)$ \\
\hline & Extended family & $106(13.3)$ \\
\hline & Fatherless nuclear families & $15(1.9)$ \\
\hline & Fatherless extended families & $14(1.7)$ \\
\hline
\end{tabular}

SD: Standard Deviation

Table 2 Comparison of scores of scales used in the study between presence and absence of prementrual syndrome

\begin{tabular}{lccc}
\hline Scale & $\begin{array}{c}\text { PMS-positive } \\
n=454 \\
\text { Mean } \pm \text { SD }\end{array}$ & $\begin{array}{c}\text { PMS-negative } \\
n=343 \\
\text { Mean } \pm \text { SD }\end{array}$ & $\begin{array}{c}\mathrm{P} \text { value } \\
121.7 \pm 27.6\end{array}$ \\
\hline The Self-Management Scale of PMS during Childrearing Periods & $141.5 \pm 26.1$ & $11.9 \pm 12.8$ & $<0.01$ \\
PMS simple test & $37.6 \pm 24.6$ & $4.5 \pm 4.2$ & $<0.01$ \\
The Edinburgh Postnatal Depression Self-Assessment Scale (EPDS) & $6.6 \pm 5.1$ & $41.8 \pm 11.2$ & $<0.01$ \\
Parenting Stress Index Short Form (General) & $44.1 \pm 12.1$ & $20.4 \pm 5.2$ & $\mathrm{n} . \mathrm{s}$. \\
Parenting Stress Index Short Form (Children's side) & $21.2 \pm 5.6$ & $21.4 \pm 5.9$ & $<0.01$ \\
Parenting Stress Index Short Form (Mothers' side) & $22.9 \pm 6.5$ & $22.1 \pm 4.9$ & n.s. \\
Social Support Scale (Husband) & $22.0 \pm 5.2$ & &
\end{tabular}

SD: Standard Deviation t: test n.s.: not signficant

for those with PMS was significantly higher $(t[770])=$ $3.31, p<0.01)$

\section{3) EPDS Scores}

The range of scores for the EPDS was 0 to 30 points. The mean postnatal depression scores were 6.6 ( $\mathrm{SD} \pm 5.1)$ for those with PMS and 4.5 (SD \pm 4.2) for those without PMS. A comparison of the mean scores for these two groups showed that the score for those with PMS was significantly higher than that of those without
PMS $(t[761.98]=6.2, p<0.01)$.

\section{4) Social Support Scale Scores}

The range of scores for the Social Support Scale was 24 to 120 points. The mean scores on the Social Support Scale (husband) were 22.0 (SD \pm 5.2) for those with PMS and 22.1 (SD \pm 4.9 ) for those without PMS, with no statistically significant difference between the scores for these two groups. 
3. Examining the Validity of the Organizational Concept 1) Operational Standards before Conducting a Factor Analysis

The factor analysis was conducted on the 454 (57.0\%) mothers with PMS. Before conducting the factor analysis, we first confirmed the ceiling and floor effects of the response distribution for the questions on the "Self-Management Scale of PMS during Childrearing Periods." There were no survey items with a ceiling effect mean score of 4.5 or greater and none with a floor effect mean score of 1.5 or lower. Next, for survey items between which the correlation was 0.7 or greater, we examined the standard deviation of the average scores for each item and eliminated the item with the larger standard deviation. In doing so, four survey items were eliminated, and we conducted the factor analysis on the remaining 44 items using principal factor analysis and promax rotation. The eliminated items included: (1) Before menstruation I get angry easily (item 10), (2) Before menstruation I am hard on my child/children (item 17), (3) Before menstruation I get irritated with my child/children (item 22), and (4) Before menstruation I am hard on my husband (partner) (item 30).

\section{2) Validity of Factor Analysis Application}

The Kaiser-Meyer-Olkin sample validity rate was 0.883 ; since this was above 0.5 , we determined that it was valid. Furthermore, the confirmation of the significance of the Bartlett sphericity test was that $\mathrm{p}<0.001$, significantly different from the identity matrix, showing the validity of applying the factor analysis.

\section{3) Factor Extraction}

In the first factor analysis, we set a standard eigenvalue of 1 or greater, which considers the cumulative contribution ratio, to decide on the number of factors. In the second factor analysis, we eliminated items with a factor loading less than 0.40 to select items and then performed a promax rotation. Three items were eliminated as a result, leaving 41 items. The eliminated items were: No7: Before menstruation I have a lower abdominal pain (item 7), (2) Before menstruation my legs are swollen (item 8), and (3) Before menstruation I get angry with my husband (partner) (item 31).

In the third factor analysis, we eliminated two items with factor loadings under 0.40 as well as items with a factor loading of 0.40 or greater that had a highly redundant factor load or were difficult to explain in the factors. We repeated the same factor analysis until the factor structure was simplified. Finally, five factors were extracted, and we decided that 38 items had meaning within these factors. The cumulative contribution ratio of the five factors was $58.350 \%$. The communality after factor extraction was 0.32 to 0.84 , and the factor loading of all items was 0.40 or greater.

First, as a result of calculating the Pearson correlation coefficient between each factor of the "Self-Management Scale of PMS during Childrearing Periods," a significant correlation was confirmed ( $r=0.21$ to 0.88 , $p<0.01)$. All items were significantly correlated $(r=$ 0.20 to $0.73, p<0.01$ to 0.05 ).
Next, as a result of performing a Good-Poor Analysis on the high-scoring group of the subscale average score $+1 / 2 \mathrm{SD}$ and greater and the low-scoring group of the mean score $-1 / 2 \mathrm{SD}$, a significant difference was confirmed $(\mathrm{t}[795]=36.285, p<0.01)$.

Factors 1 and 4 were moderately correlated $(r=0.64$, $p<0.01)$. There were weak correlations between the following pairs of factors: 1 and $2(r=0.22, p<0.01) ; 1$ and $5(r=0.27, p<0.01) ; 2$ and $3(r=0.36, p<0.01) ; 2$ and $4(r=0.27, p<0.01)$; and 4 and $5(r=0.29, p<0.01)$ (see Table 3).

4) Factor Structure of the "Self-Management Scale of PMS during Childrearing Periods" (see Table 3)

Factor 1 consisted of 10 items, including "I cannot control my feelings before menstruation" and "I get angry at my child before menstruation," and we named this factor "Premenstrual emotional instability." Factor 2 consisted of 10 items including "I feel like parenting is fun after I start menstruating" and "I can be more kind to my child after I start menstruating," and we named this factor "positive emotional changes after the onset of menstruation." Factor 3 consisted of six items including "my husband takes good care of me after I start menstruating" and "my husband takes good care of me before I start menstruating," and we named this factor "mothers' perspective on support provided by their husbands (partners) before/after the onset of menstruation." Factor 4 consisted of 10 items including "my job gets more tiresome before menstruation" and "I feel like no one supports me before menstruation," and we named this factor "lowered premenstrual energy." Factor 5 consisted of four items including "my head feels heavy before menstruation" and "I get stiff shoulders before menstruation," and we named this factor "unpleasant premenstrual physical symptoms ."

\section{5) Scores on the "Self-Management Scale of PMS during Childrearing Periods"}

The scores for the "Self-Management Scale of PMS during Childrearing Periods" ranged from 48 to 223 points, and the mean score was $133.3(\mathrm{SD} \pm 27.7)$. The mean score for those with PMS was 141.5 (SD \pm 26.1$)$, and the mean score for those without PMS was 121.7 $(\mathrm{SD} \pm 27.6)$. In comparing the "Self-Management Scale of PMS during Childrearing Periods" scores for those with and without PMS, the score for the former was significantly higher than the score for the latter $(t[829]=$ $10.6, \mathrm{p}<0.01)$.

\section{Examining the Criterion Validity of the "Self-Man- agement Scale of PMS during Childrearing Periods" \\ 1) Correlation between the "Self-Management Scale of PMS during Childrearing Periods" and the PSI-SF}

Results from the correlation between the "Self-Management Scale of PMS during Childrearing Periods" and the PSI-SF indicated that there were weak positive correlations for the stress in the child sides: "feeling of emotional instability before menstruation" ( $r=0.31, p<$ 0.01 ) and "lowered energy before menstruation" ( $r=$ $0.36, p<0.01)$. The correlations for the stress in the 


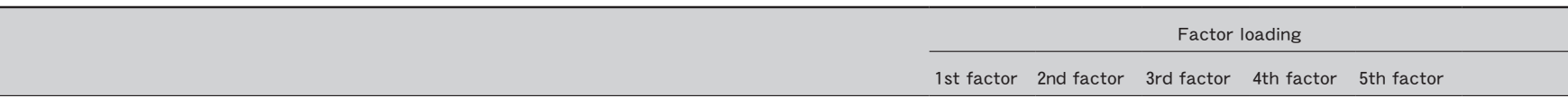

1st factor "Premenstrual emotional instability"

11 Before menstruation I can not control my feelings

12 Before menstruation I get aggressive

18 Before menstruation I get angry at my child/children

16 Before menstruation I find my child/children noisy

9 Before menstruation I get irritated

21 Before menstruation I can not tolerate usual behaviors of my child/children

14 Before menstruation I feel uneasy

15 Before menstruation I am easily moved to tears /I cry easily

13 Before menstruation I feel depressed

19 Before menstruation I smack my child/children

\begin{tabular}{|c|c|c|c|c|c|}
\hline 0.895 & -0.048 & -0.019 & -0.087 & 0.066 & 0.727 \\
\hline 0.862 & 0.056 & -0.097 & -0.114 & 0.071 & 0.692 \\
\hline 0.773 & 0.067 & -0.004 & 0.120 & -0.165 & 0.702 \\
\hline 0.720 & -0.032 & 0.022 & 0.173 & -0.035 & 0.679 \\
\hline 0.667 & 0.056 & 0.052 & -0.137 & 0.223 & 0.489 \\
\hline 0.561 & 0.099 & -0.027 & 0.256 & -0.143 & 0.561 \\
\hline 0.520 & -0.017 & 0.068 & 0.163 & 0.092 & 0.445 \\
\hline 0.497 & -0.003 & 0.051 & 0.171 & 0.054 & 0.407 \\
\hline 0.478 & -0.039 & 0.073 & 0.162 & 0.259 & 0.503 \\
\hline 0.444 & -0.041 & -0.032 & 0.197 & -0.124 & 0.702 \\
\hline-0.071 & 0.913 & 0.002 & -0.024 & 0.021 & 0.810 \\
\hline-0.048 & 0.887 & 0.011 & 0.050 & 0.018 & 0.809 \\
\hline-0.144 & 0.822 & 0.078 & 0.085 & 0.065 & 0.751 \\
\hline-0.074 & 0.808 & 0.018 & 0.069 & 0.022 & 0.679 \\
\hline-0.151 & 0.736 & 0.108 & 0.164 & 0.046 & 0.661 \\
\hline 0.199 & 0.703 & -0.104 & -0.225 & -0.059 & 0.448 \\
\hline 0.234 & 0.693 & -0.093 & -0.241 & -0.019 & 0.459 \\
\hline 0.157 & 0.622 & 0.237 & -0.087 & -0.106 & 0.552 \\
\hline
\end{tabular}

2nd factor "Positive emotional changes after the onset of menstruation"

40 With the onset of my menstruation I can enjoy child- rearing

39 With the onset of my menstruation I can be nice to my child/children

37 With the onset of my menstruation I enjoy being with my child/children

38 With the onset of my menstruation I can tolerate naughty behaviors of my child / children

36 With the onset of my menstruation I find my child/children adorable

41 With the onset of my menstruation I can increase efficiency in house chores

42 With the onset of my menstruation I can increase efficiency at work

43 With the onset of my menstruation I can be nice to my husband (partner)

3rd factor "Mothers' perspective on supports provided by their husbands (partners) before/after the onset of menstrua-

48 With the onset of my menstruation I feel my husband takes good care of me

47 With the onset of my menstruation I feel my husband (partner) can relate to my discomfort

46 With the onset of my menstruation I feel I can get emotional support from my husband (partner)

45 With the onset of my menstruation I feel I can get child-rearing support from my husband (partner)

35 Before menstruation I feel my husband (partner) takes good care of me

34 Before menstruation I feel my husband (partner) can relate to my discomfort

\begin{tabular}{rr|r|rrr}
\cline { 3 - 3 } 0.017 & -0.022 & 0.931 & 0.007 & -0.018 & 0.848 \\
-0.033 & -0.037 & 0.892 & 0.040 & 0.013 & 0.772 \\
-0.009 & 0.094 & 0.866 & 0.073 & -0.053 & 0.803 \\
0.037 & 0.098 & 0.850 & 0.062 & -0.101 & 0.776 \\
0.015 & 0.032 & 0.732 & -0.048 & 0.034 & 0.566 \\
-0.024 & 0.038 & 0.661 & -0.095 & 0.093 & 0.495
\end{tabular}

4th factor "Premenstrual lowered energy"

25 Before menstruation I am reluctant to work

26 Before menstruation I feel nobody understands me

27 Before menstruation I feel nobody supports me

23 Before menstruation I am reluctant to take care of my child/children

24 Before menstruation I am reluctant to do house chores

28 Before menstruation I hate being a woman

29 Before menstruation I find my husband (partner) annoying

20 Before menstruation I want to be left alone from my child/children

32 Before menstruation I feel I don't get child-rearing support from my husband (partner)

33 Before menstruation I feel I don't get emotional support from my husband (partner)

$-0.105$

0.142

0.135

0.219

0.047

0.070

0.095

0.342

$-0.054$

$-0.036$

$-0.083$

0.012

0.028

$-0.069$

$-0.028$

$-0.145$

$-0.032$

$-0.058$

0.150

0.171

0.16
-0.104
-0.125
0.075
0.138
0.08
-0.088
0.08
-0.395
-0.4

0.162
-0.104
-0.125
0.075
0.138
0.080
-0.088
0.086
-0.395
-0.441

\subsection{3}

$0.696-0.082$

$0.668-0.060$

$0.665-0.026$

$0.657 \quad 0.128$

$\begin{array}{ll}0.600 & -0.032\end{array}$

$0.578 \quad 0.050$

$0.513-0.108$

$0.496 \quad 0.051$

0.486

0.006

0.554

0.595

0.626

0.631

0.536

0.368

0.441

0.538

0.432

0.461

5 th factor "Premenstrual physical unpleasant conditions"

4 Before menstruation I feel heavy -headed

5 Before menstruation I have a headache

2 Before menstruation I have stiff shoulder

3 Before menstruation I feel fatigue

\begin{tabular}{rrrrrrr} 
& 0.032 & -0.052 & -0.030 & -0.007 & 0.872 & 0.751 \\
& -0.054 & -0.043 & 0.004 & 0.014 & 0.761 & 0.554 \\
& 0.099 & 0.077 & -0.046 & 0.019 & 0.509 & 0.326 \\
& 0.135 & 0.134 & 0.020 & 0.110 & 0.477 & 0.408 \\
\hline Eigenvalue & 10.330 & 6.787 & 3.045 & 2.202 & 1.748 & \\
Factor contribution ratio & 26.063 & 17.018 & 7.131 & 4.676 & 3.462 & \\
Cumulative contribution ratio & 26.063 & 43.080 & 50.212 & 54.888 & 58.350 &
\end{tabular}

\begin{tabular}{|c|c|c|c|c|c|}
\hline \multicolumn{6}{|l|}{ Factor correlation } \\
\hline Factor & 1st factor & 2nd factor & 3rd factor & 4th factor & 5 th factor \\
\hline 1st factor "Premenstrual emotional instability" & 1 & 0.221 & -0.008 & 0.635 & 0.273 \\
\hline 2nd factor "Positive emotional changes after the onset of menstruation" & & 1 & 0.358 & 0.267 & 0.227 \\
\hline $\begin{array}{l}\text { 3rd factor "Mothers' perspective on supports provided by their husbands (partners) before/after the onset of menstrua- } \\
\text { tion" }\end{array}$ & & & 1 & -0.079 & 0.117 \\
\hline 4th factor "Premenstrual lowered energy" & & & & 1 & 0.287 \\
\hline 5th factor "Premenstrual physical unpleasant conditions" & & & & & 1 \\
\hline
\end{tabular}


Table 4 Correlation between the Self-Management Scale of PMS during Childrearing Periods and the Parenting Stress Index Short Form (PSI-SF)

$(n=454)$

\begin{tabular}{|c|c|c|c|c|c|}
\hline & 1st factor & 2nd factor & 3rd factor & 4th factor & 5th factor \\
\hline 1. Stress of child attachment & $0.290^{* *}$ & -0.006 & $-0.145^{* *}$ & $0.361^{* *}$ & -0.040 \\
\hline 2. Stress of difficulty in raising children & $0.284^{* *}$ & -0.027 & $-0.165^{* *}$ & $0.315^{* *}$ & -0.003 \\
\hline 3. Stress from children's side (Subtotal) & $0.315^{* *}$ & -0.017 & $-0.171^{* *}$ & $0.367^{* *}$ & -0.022 \\
\hline 4. Stress of sense of burden in childrearing & $0.374^{* *}$ & 0.002 & $-0183^{* *}$ & $0.475^{* *}$ & $0.099^{*}$ \\
\hline 5. Stress associated with relationship between mother and husband & $0.195^{* *}$ & -0.061 & $-0.441^{* *}$ & $0.383^{* *}$ & 0.048 \\
\hline 6. Stress from mothers' side (Subtotal) & $0.362^{* *}$ & -0.017 & $-0.297^{* *}$ & $0.508^{* *}$ & 0.092 \\
\hline
\end{tabular}

Correlation coefficient: Pearson's ${ }^{* *} \mathrm{p}<0.01 \quad$ "p $<0.05$

Table 5 Correlation between the Self-Management Scale of PMS during Childrearing Periods and the Edinburgh Postnatal Depression Scale

$(\mathrm{n}=454)$

\begin{tabular}{|c|c|c|c|c|c|}
\hline & 1st factor & 2nd factor & $3 r d$ factor & 4th factor & 5th factor \\
\hline $\begin{array}{l}\text { The Edinburgh Postnatal Depression Self-Assessment Scale } \\
\text { (EPDS) }\end{array}$ & $0.308^{* *}$ & 0.017 & -0.119 & $0.348^{* *}$ & $0.199^{* *}$ \\
\hline
\end{tabular}

Correlation coefficient: Pearson’s ${ }^{* *} \mathrm{p}<0.01 \quad$ " $\mathrm{p}<0.05$

Table 6 Correlation between the Self-Management scale of PMS during Childrearing Periods and the Social Support Scale ( $=454)$

\begin{tabular}{lrrrrr}
\hline & 1st factor & 2nd factor & 3rd factor & 4th factor & 5th factor \\
\hline 1. Social support (Husband) & $-0.185^{* *}$ & 0.079 & $0.506^{* *}$ & $-0.326^{* *}$ & -0.064 \\
2. Social support (Parents) & $-0.186^{* *}$ & 0.044 & $0.136^{* *}$ & $-0.219^{* *}$ & -0.004 \\
3. Social support (Friends) & $-0.200^{* *}$ & -0.012 & $0.115^{*}$ & $-0.255^{* *}$ & -0.018 \\
4. Social support (Neighbors) & -0.081 & 0.088 & $0.142^{* *}$ & $-0.101^{*}$ & 0.021 \\
\hline
\end{tabular}

Correlation coefficient: Pearson's ${ }^{* *} \mathrm{p}<0.01 \quad{ }^{*} \mathrm{p}<0.05$

mother sides were as follows: a weak positive correlation with "feeling of emotional instability before menstruation" ( $r=0.36, p<0.01)$ and a relatively strong positive correlation with "lowered energy before menstruation" $(r$ $=0.50, p<0.01$ ). There was a weak negative correlation with "perception of husband's (partner's) support before and after menstruation" ( $r=-0.29, p<0.01)$. (see Table 4)

2) Correlation between the "Self-Management Scale of PMS during Childrearing Periods" and the EPDS

Results from the correlation between the "Self-Management Scale of PMS during

Childrearing Periods" and the EPDS indicated that there were weak positive correlations with "feeling of emotional instability before menstruation" ( $r=0.30, p<$ 0.01 ) and "lowered energy before menstruation" ( $r=$ $0.34, p<0.01)$. There was a moderately negative correlation with "perception of husband's (partner's) support before and after menstruation" $(r=-0.44, p<0.01)$. (see Table 5)

3) Correlation between the "Self-Management Scale of PMS during Childrearing Periods" and the Social Support Scale

Results from the correlation between the "Self-Management Scale of PMS during Childrearing Periods" and the Social Support Scale subscale indicated that there was a moderately positive correlation between the "husband social support scale" and the "perception of husband's (partner's) support before and after menstruation" $(r=0.50, p<0.01)$. There was a weak negative correla- tion with "lowered energy before menstruation" ( $r=$ $-0.32, p<0.01)$. There was a weak, negative correlation between the "parent social support scale" and "lowered energy before menstruation" ( $r=-0.21, p<0.01)$. There was a weak correlation between the "friend social support scale" and "feeling of emotional instability before menstruation" ( $r=-0.20, p<0.01)$ and "lowered energy before menstruation" ( $r=-0.25, p<0.01)$. (see Table 6)

\section{Examining the Reliability of the "Self-Management Scale of PMS during Childrearing Periods" \\ 1) Examining Internal Consistency}

We calculated Cronbach's $\alpha$ for the entire scale and for each of the five factors to confirm the reliability of the "Self-Management Scale of PMS during Childrearing Periods." The Cronbach's $\alpha$ for the entire scale was 0.92. The Cronbach's $\alpha$ for each factor was as follows: Factor 1 "feeling of emotional instability before menstruation": 0.91; Factor 2 "positive emotional changes after menstruation": 0.92; Factor 3: "perception of husband's (partner's) support before and after menstruation": 0.94; Factor 4 "lowered energy before menstruation": 0.89; and Factor 5 "unpleasant physical symptoms before menstruation": 0.79 . All factors had values of 0.70 or greater, confirming high internal consistency.

2) Examining Reliability using the Split-Half Method

With the split-half method, we used split-half odd and even numbers to find the correlation coefficient and substituted this into the Spearman-Brown formula to find the reliability coefficient. The result was that $\rho=0.74$, 
showing that the confidence coefficient exceeded the standard of 0.70 .

\section{Discussion}

\section{Examining the Validity of the "Self-Management Scale of PMS during Childrearing Periods"}

1) Examining the Content Validity of the "Self-Management Scale of PMS during Childrearing Periods"

The questions comprising the "Self-Management Scale of PMS during Childrearing Periods" included symptoms during the 34 cycles of basal body temperature that were extracted from the charts of 12 mothers diagnosed with PMS currently raising children aged one to three years. According to the diagnostic criteria of the America College of Obstetricians and Gynecologists (ACOG) ${ }^{27}$ the diagnosis of PMS symptoms is based on self-confirmation of the prospective recurrence of symptoms over three cycles by the PMS patient. That is, by reflecting on the real-time records of basal body temperature charts including symptoms toward the children of mothers in their childrearing period as well as expert opinions of premenstrual symptoms during childrearing years, it is thought that, because the items were further refined, we were able to confirm content validity.

\section{2) Examining Organizational Validity}

The "Self-Management Scale of PMS during Childrearing Periods" consisted of 38 items and five factors. The factors extracted were "feeling of emotional instability before menstruation," "positive emotional changes after menstruation," "perception of husband's (partner's) support before and after menstruation," "lowered energy before menstruation," and "unpleasant physical symptoms before menstruation." The American Society for Reproductive Medicine (1997) ${ }^{28}$ indicates 9 psychiatric, 14 physical, and 12 behavioral symptoms of PMS. Furthermore, past research suggests that women in their 30s and 40s are most commonly diagnosed with PMS. The subjects in this study had an average age of 34.65 (SD \pm 4.8) years (ranging from 20 to 44 years). Thus, these mothers were in the age range of women typically diagnosed with PMS. In this study, $57.0 \%$ of participants had PMS, which is somewhat higher than the $20-40 \%$ reported in previous studies. ${ }^{29,30}$ According to Kawase et al, ${ }^{4}$ women who had given birth had significantly higher emotional and social symptoms than those who had not, including the following: becoming irritated, being easily angered, becoming aggressive, believing oneself to be unimportant, and having an inability to manage one's health. In the scale developed in this study as well, the factors consisting of emotional and social symptoms concomitant with PMS during the childrearing period, such as "feeling of emotional instability before menstruation" (which included becoming aggressive, becoming irritated, and getting angry at one's child before menstruation) and "lowered energy before menstruation" (which included parenting becoming tiresome and hating being a woman before menstruation) were extracted ahead of the factor "unpleasant physical symp- toms before menstruation" (which included head feeling heavy and shoulders getting stiff before menstruation).

Kashiwagi and Wakamatsu ${ }^{31}$ state that the husband's proactive participation in childrearing greatly reduces the wife/mothers' negative feelings. Hattori and Harada ${ }^{32}$ also state that the husband's participation and cooperation not only impact the mother's emotional stability but also have positive effects in all sides of the mother's attitude and specific content of childrearing. There were no significant differences between mothers with/without PMS, which suggests that their "perception of husband's (partner's) support before and after menstruation" was not determined by the severity of PMS symptoms but rather influenced by their husband's involvement in childrearing. Therefore, their positive perceptions reduced "feeling of emotional instability before menstruation" and "lowered energy before menstruation," which is believed to give the mothers emotional stability; thus, it is conceivable that we obtained construct validity.

\section{3) Examining the Criterion Validity}

For criterion validity, we analyzed the correlation between the total scores of the scale developed in this study with the total subscale scores of the PSI-SF, EPDS, and Social Support Scale as concurrent validity. The results showed a weak positive correlation between the "PMS Self-Management Scale During Childrearing Period" and the child components of the PSI-SF for "feeling of emotional instability before menstruation" and "lowered energy before menstruation." The burden of parenting in the mother sides showed a weak positive correlation with "feeling of emotional instability before menstruation" and a relatively strong positive correlation with "lowered energy before menstruation." It had a weak negative correlation with "perception of husband's (partner's) support before and after menstruation." Higher scores for the PSI-SF enabled assessments of high stress related to children and high stress levels of the mother herself. Higher scores on the scale developed in this study also indicated stronger premenstrual symptoms. The positive correlation between this scale and the PSI-SF suggests there is concurrent validity. Additionally, there was no correlation observed between "positive emotional changes after menstruation" and the PSI-SF. This may be due to the fact that as the emotional symptoms that accompany PMS disappear with the start of menstruation or within four days from the start of menstruation, the relationship between parenting stress and PMS symptoms also disappears. The definition of PMS is "physical, mental, and social symptoms that begin at least 3 to 10 days before the start of menstruation and that disappear when menstruation starts or within four days of the start of menstruation.” This scale demonstrated the same sides as the definition of PMS with "unpleasant physical symptoms before menstruation," "feeling of emotional instability before menstruation," and "lowered energy before menstruation" for the premenstrual period and "positive emotional changes after menstruation" showing that symptoms disappear after the onset of menstruation. 
Furthermore, there was a weak negative correlation between the "husband social support scale" and "reduced energy before menstruation." There was a weak negative correlation between the "parent social support scale" and "lowered energy before menstruation." There were weak negative correlations among the "friend social support scale" and "feeling of emotional instability before menstruation" and "lowered energy before menstruation." Higher scores on the "social support scale" signify higher degrees of social support. However, on this study's scale, strong premenstrual symptoms in mothers during the childrearing period indicated higher scores. The negative correlation between this study's scale and the "social support scale" indicate that concurrent validity was obtained.

\section{Examining the Reliability of the "Self-Management Scale of PMS during Childrearing Periods"}

The Cronbach's $\alpha$ for the "Self-Management Scale of PMS during Childrearing Periods" was 0.91, and the confidence coefficients for the subscales ranged from 0.79 to 0.92 . According to Oshio, Atsushi, and Nishiguchi, ${ }^{33}$ if Cronbach's $\alpha$ is 0.80 or greater, the internal consistency of the scale is satisfactory. The "PMS Self-Management Scale During Childrearing Period” meets this standard. Furthermore, in the split-half Spearman-Brown method, high reliability was confirmed with $\rho=0.74$. These results demonstrate that the "Self-Management Scale of PMS during Childrearing Periods" is reliable.

\section{The Usefulness of the "Self-Management Scale of PMS during Childrearing Periods"}

When nurses examine the childrearing support for mothers who have PMS during their childrearing period, they must recognize that premenstrual symptoms related to PMS can influence childrearing, housework, and employment. Issues surrounding menstruation-associated symptoms, including PMS and Premenstrual Dysphoric Disorder (PMDD) during the childrearing period, are not widely acknowledged in Japan by mothers, husbands (partners), and families; because symptoms improve with the start of menstruation, it is surmised that many mothers themselves do not notice premenstrual symptoms. The reliability and validity of the "Self-Management Scale of PMS during Childrearing Periods" was confirmed in this study. Thus, by using the "Self-Management Scale of PMS during Childrearing Periods" during waiting times for infant health checkups, there is a possibility for mothers to recognize PMS-related symptoms, prevent reduced quality of life for mothers, and lessen the risk of infant abuse by avoiding irritation towards children leading up to menstruation.

\section{Study Limitations and Future Directions}

The subjects of this study were mothers whose youngest child was attending preschool or kindergarten and who were in an environment in which it would be easy to get support from childcare workers or kindergar- ten teachers if they wanted to discuss childrearing concerns. Going forward, we would like to increase participation to mothers whose children are on a preschool waiting list, who are socially isolated and unable to receive support from childcare experts, who have ill children, and who have children with disabilities in order to demonstrate the usefulness of the "Self-Management Scale of PMS during Childrearing Periods" for mothers whose menstruation has begun two months and on after giving birth.

Tailor' ${ }^{34}$ program for building self-care abilities, the "Premenstrual Syndrome Symptom Supervisory Program," has been evaluated as effective for PMS.

In accordance with the amendment to the Mother and Child Health Act in April 2017, municipalities of Japan are required to establish a Childrearing Generation Comprehensive Support Center. The scale developed in this study is expected to be utilized for mothers whose menstruation has resumed, at hospitals, clinics, maternity hospitals, and other locations providing after childbirth care. Also, the scale can be used on the during the child's 18-month and 3-year medical checkups and vaccinations, as well as before and after health education on PMS for postnatal women.

\section{Acknowledgements}

We would like to express our deepest thanks to the study participants for their cooperation and to the people at each affiliated facility who cooperated in data collection. This study was supported by JSPS KAKENHI Grant Number 23593330.

\section{References}

1. Dalton K. (trans. Kodama, Y). PMS Baiburu: gekkeizen-shokogun no subete (The PMS Bible: All about premenstrual syndrome). Tokyo: Gakujutsu Shoin, 2007: 138-145 (in Japanese).

2. Deysterer A, South-Paul J. Biological, social, and behavioral factors associated with premenstrual syndrome. Arch Fam Med 1999; 8: 122-128.

3. Mori K, Kawase Y, Yoshizaki M, et al. Raifusutairu to PMS to no kanren ni tsuite no kento (Study on the relationship between lifestyle and PMS). J Jpn Soc Psychosom Obstet Gynecol 2004; 9: 134-145.

4. Kawase K, Mori K, Yoshizaki A, et al. Honpo ni okeru seijuku josei no PMS no jittai (The reality of mature women's PMS in Japan). J Jpn Soc Psychosom Obstet Gynecol 2004; 9: 119-133.

5. Watanabe K, Toda M, Saikai H. Gekkeizen shokogun ni okeru sutoresu to seikatsu shukan to no kanren bunseki (Analysis of the relationship between stress and lifestyle in premenstrual syndrome). J Jpn Soc Matern Health 2012; 1: 437-443.

6. American Society of Reproductive Medicine. Premenstrual syndrome (PMS): A guide for patients. Am Soc Reprod Med 1997; 3-11.

7. Freeman EW. Premenstrual syndrome and premenstrual dysphoric disorder: Definitions and diagnosis. Psychoneuroendocrinology 2003; 28(Suppl 3): 25-37.

8. Freeman EW, Sondheimer SJ. Premenstrual dysphoric disorder: Recognition and treatment. Prim care companion. J 
Clin Psychatry 2003; 5: 30-39.

9. Dalton K (trans. Kodama Y). PMS houtei ni iku: gekkeizen-shokogun to josei no hanzai: [PMS in the courtroom: Premenstrual syndrome and female crime]. Tokyo: Seishin Shobo, 1998; 71-72 (in Japanese).

10. Dalton K. The influence of mother's menstruation on her child. Proc R Soc Med 1966; 1014-1016.

11. Lewis J. Premenstrual syndrome as Criminal Defense. Archives of Sexual Behavior, 1990; 19: 425-441.

12. Japan Society of Obstetrics and Gynecology. Sanfujinka Shinryo Gaidorain Sanka-hen 2017; (Obstetrics and Gynecology Medical Care Guideline, Obstetrics version 2017): 239242 (in Japanese).

13. Harada M. Nihon no kosodate genba no okina henbo wo utsushidasu "hyogo repoto" (The "Hyogo Report" depicting a great transformation in childrearing sites in Japan). Pub Health Nurs J1 2004; 60: 600-605 (in Japanese).

14. Hamasaki M. Gekkeizen-shokogun wo yusuru hahaoya no sutoresu taisho katei (The stress coping mechanisms of mothers with premenstrual syndrome). Gunma University Faculty of Medicine School of Health Sciences master's thesis, 2005: 1-100 (in Japanese).

15. Namba S. Kango-kei joshidaisei no nichijoseikatu sutoresu to gekkeizuihanshojo to narabini sosharu sapoto to no kanren ni tsuite (On relationship between daily life stress, symptoms associated with menstruation, and social support in the female students of college of nursing). Maternal Health, 2000; 41: 235-241 (in Japanese).

16. Japan Society of Obstetrics and Gynecology, ed. Sanka fujinka yogoshu, yogo kaisetsushu (Obstetrics and gynecology vocabulary and glossary collection, 3rd revised edition). Tokyo: Kanehara Publishing, 2013; 175-176 (in Japanese).

17. Barlow J, Wright C, Sheasby J, et al. Self-management approaches for people with chronic conditions a review. Patient Educ Couns 2002; 48: 177-187.

18. Kawase K. Nayandeiru no wa PMS desu ka soretomo PEMS desu ka (Is it PMS bothering you or PEMS?). In: Matsumoto S (ed.). Gekkei rakuraku koza (Course on trouble-free menstruation). Tokyo: Bunkodo, 2006: 18-27 (in Japanese).

19. Kawase K. Gekkei no kenkyu (Menstruation studies). Tokyo: Kawashima Shoten 2006; 183-214 (in Japanese).

20. Kawase K, Mori K, Suzuki S, et al. Gekkeizen shojo no sokujiteki kirokuho no kento: PMS memori no kaihatsu (Study on instant recording of premenstrual symptoms: Developing PMS memori). J Jpn Soc Psychosom Obstet Gynecol 2000; 5: 31-37.

21. Abidin RR. Parenting stress index manual, 1st ed. Charlottesville, VA: 1983.

22. Araki A, Kanematsu Y, Yokosawa S, et al. Ikuji sutoresu shoto fomu no kaihatsu ni kan suru kenkyu (Study on the development of the childrearing stress short form). J Child
Health 2005; 64: 408-416 (in Japanese).

23. Narama M, Kanematsu Y, Araki A, et al. Nihonban Parenting Stress Index (PSI) no shinraisei datosei no kento (Study on the reliability and validity of the Japan Edition, Parenting Stress Index (PSI)). J Child Health 1999; 58: 610-616 (in Japanese).

24. Cox JL, Holden JM, Sagovskey R. Detection of postnatal depression. Development of the 10-item Edinburgh Postnatal Depression Scale. Brit J Psychiat 1987; 150: 782-786.

25. Okano T. Nihongoban ejinbara sango utsubyo jiko hyokahyo (EPDS) no shinraisei to datosei (Reliability and validity of the Japanese Version of the Edinburgh Postnatal Depression Scale, (EPDS)). J Psychiatr Diag 1996; 7: 525-533 (in Japanese).

26. Nakamura M, Kanematsu Y, Yokota M. Mansei shikkan kanji to kenkoji no sosharu sapoto (Social suport for infants with chronic illnesses and healthy children). Jpn J Nurs Sci 1997; 17: 40-47 (in Japanese).

27. ACOG. Practice bulletin premenstrual syndrome compendium of selected publications. Washington, DC: ACOG, 2005: 707-713.

28. Watanabe K, Kita A. Bunkenteki kento ni yoru gekkei shuhenki shojo no kasetsuteki kango puroguramu moderu no kochiku (Constructing a hypothetical nursing program model for symptoms in the period surrounding menstruation through a literature analysis). 2004; 20: 95-108 (in Japanese).

29. Sagara Y, Kuwabara Y, Mizuno M. Honpo ni okeru gekkeizen-shokogun no ekigakuteki jiko to sono shindan ni okeru mondaiten (Epidemiological facts of premenstrual syndrome and issues with its diagnosis). Obstet Gynecol Pract 1991; 40: 1235-1241 (in Japanese).

30. Sadler C, Smith H, Bayly R, et al. Lifestyle factors hormonal contraception and premenstrual symptoms. The United Kingdom Southampton women's survey. J Womens Health 2010; 19: 391-396.

31. Kashiwagi K, Wakamatsu M. "Oya to naru” koto ni yoru jinkaku hattatsu, shogai hattatsuteki shiten kara oya wo kenkyu suru kokoromi (Personality development through "becoming a parent" and attempting to study parents from a lifelong developmental perspective). Jpn J Dev Psychol 1994; 5: 72-83.

32. Hattori S, Harada M. Nyuyoji no shinshin hattatsu to kankyo: Osaka repoto to seishin igakuteki shiten (Infants' psychological development and environment: Osaka report and psychiatric perspective). Nagoya: Nagoya University Publishing, 1996: 213-247 (in Japanese).

33. Oshio A, Nishiguchi T. Shitsumonshi chosa no tejun (Questionnaire survey procedures). Tokyo: Nakanishiya Publishing, 2012: 103 (in Japanese).

34. Tailor D. Effectiveness of professional peer group treatment, symptom management for women PMS. Res Nurs Health 1999; 22: 496-511. 